\title{
2 Interdisciplinary and transdisciplinary approaches to ageing and gerontology
}

\author{
Angus McMurtry and Jenny Sasser
}

This chapter articulates and practically illustrates what it would mean to consider the complex multifaceted phenomena of ageing in an interdisciplinary and/or transdisciplinary manner that is, by considering and integrating biomedical, experiential, sociological, economic, stakeholder engagement and many other factors. A rich literature on interdisciplinary and transdisciplinary research and education has emerged in recent decades. In the fields of ageing and gerontology, however, researchers and educators have mostly proceeded in merely disciplinary or multidisciplinary manners. In addition, the authors argue that interdisciplinary and transdisciplinary methodologies prompt novel epistemological frameworks that transcend traditional assumptions about objectivity, subjectivity and correspondence.

\section{Introduction}

It will likely come as a surprise to no one if we say that ageing is a complex and multifaceted phenomenon, arguably the central experience in our life journey. What is surprising is that most researchers investigate this topic through single disciplinary and epistemological lenses. For example, one researcher might adopt a quantitative positivist biomedical approach to research neurological changes, while another might use post-structural and sociologically informed qualitative interviews to make sense of intergenerational relationships. While valuable, these narrow perspectives are limited - not only conceptually, because they can provide only a partial view, but also practically, because taken in isolation they fail to consider whole persons and how they are situated in particular times, places and spaces.

In this chapter, we review disciplinary, multidisciplinary, interdisciplinary and transdisciplinary thinking in general and in relation to ageing research and gerontology specifically. To practically illustrate these differing approaches, we will apply them to a case we have created. As we shall see, ageing and gerontological research already takes multiple disciplinary forms. These diverse insights are, however, rarely integrated (or even held together) in an interdisciplinary or transdisciplinary manner.

The complexity of the ageing experience is rarely foregrounded and gerontological inquiry and practice often fails to be predicated upon and informed by the experiences and participation of stakeholders like ageing people themselves - key principles of transdisciplinary research and activities.

Finally, we will discuss how interdisciplinary and transdisciplinary research and action prompt us to transcend traditional dualisms of objectivity and subjectivity, as well as the 
assumption that knowledge must be framed in terms of correspondence between objective realities and subjective representations. This more progressive view of knowing in turn offers a strong recommendation for adopting more transdisciplinary approaches to ageing and gerontology.

\section{Definitions}

Before exploring the above issues, however, we should clarify several terms that will be used frequently in this chapter.

Multidisciplinary activities draw upon two or more disciplinary perspectives in order to better understand or address a certain issue or problem. Interdisciplinary is used to describe activities that also attempt to integrate such disciplinary perspectives in a way that may lead to the development of new, overarching knowledge that transcends these perspectives (Klein, 2017; Repko, 2012). Interdisciplinary approaches are often used to study "wicked" problems whose complexity resists uni-disciplinary or simple explanation.

Transdisciplinary appears at several points in this chapter. There are at least two ways in which this term is used in current discourse. One is employed by a team of science researchers based primarily in the United States. They define transdisciplinary research as the development of "shared conceptual and methodological frameworks that not only integrate but transcend their respective disciplinary perspectives" (Klein, 2017: 79). This definition is compatible with the definition of interdisciplinarity above.

Another definition of transdisciplinary - one that will strongly inform our discussion in this chapter - is problem-driven research that involves collaboration among not only diverse academic researchers (like interdisciplinarity) but also non-academic stakeholders (Klein, 2017). These stakeholders could be members of a local community pursuing sustainable development; or patients, family members or health lobby groups seeking input into the health research, policy or practice that affects them or those whom they represent.

However, disciplinary diversity and stakeholder engagement are not, alone, sufficient to make research transdisciplinary in this latter sense. Other authors have stressed the importance of collaborative and inclusive processes (Sasser, 2017); engagement in a particular kind of ongoing praxis (Augsburg, 2014); a focus on "wicked" problems needing creative solutions and engaged, socially responsible research (Bernstein, 2015); and a focus on context, reflexivity and outcomes that are "not easily measurable or subject to traditional, reductionist forms of quality control" (Byrne, Mullally and Sage, 2016).

\section{Ageing and gerontology}

Ageing is a universal feature of human life, although its expression is exceptionally heterogeneous because of the mediating forces of biology, economics, culture, social structures, environment and history. Put another way, all human beings experience ageing as they travel through the life-course, but ageing unfolds within individual lives; as such, there are as many ageing experiences as there are individuals who are ageing. Furthermore, ageing can be studied from a variety of disciplinary perspectives, including geriatric medicine and social work, social and health policy, the traditional human sciences, business, technology, ethics, legal theory, nutrition, public health, leisure studies ... to name just a few!

Gerontology is commonly described as the academic area of research, theory and practice subsumed within the larger field of ageing. Gerontology is concerned with the multifaceted and complex aspects of adult ageing - biological, psychological, social, 
cultural, technological, political, economic - as well as the policies and programs associated with adult ageing. What differentiates gerontology from related fields of study as well as allied disciplines is that its "unit of analysis" is the universal phenomenon of human ageing.

\section{Illustrative case}

It was during a two-week trip together that Sylvia's mid-life daughter and young adult granddaughter became quite alarmed. Throughout the trip as well as in the weeks afterward, Sylvia, who was 73 years of age at the time of the trip, seemed quite confused and struggled with activities such as deciding what to eat, keeping track of her schedule and participating in conversations. She complained of back pain, slept a lot and was frequently impatient and disgruntled. Sylvia's daughter and granddaughter each alone and then together expressed their concerns to her; her response alternated between bouts of uncontrollable crying, and defensiveness, denial and anger.

Sylvia had experienced anxiety and depression for as long as they could remember and while she had been prescribed various combinations of prescription medications to try to manage her symptoms, she'd participated only briefly and intermittently in mental health counseling. A decade previously, Sylvia had survived a serious stroke which fortunately resulted in only residual mild cognitive impairment, though recent routine neuro imaging had revealed the possibility of vascular dementia. Another co-morbidity, hearing loss, had grown increasingly worse to the extent that hearing aids, which she wore in social situations, seemed mostly unhelpful.

Sylvia had been living independently in a congregate senior housing community for the past several years in the same neighborhood where her daughter and her family live. She moved to the community after her most recent relationship ended abruptly. Sylvia had been married previously twice and in several other serious co-habitation relationships; each relationship had involved some degree of domestic violence and economic insecurity. Her post-work years - she had worked full time until her stroke a decade earlier - have fortunately been more economically secure as she receives social security, a pension and a monthly stipend from an inheritance from her parents.

While Sylvia has a small group of close friends, they tend to turn-over regularly and be replaced by new friends. When she's experiencing a bout of anxiety and depression, she often self-isolates from both friends and family. As well, while she has some abiding interests - walking, reading, gardening and attending cultural events - her participation in them is inconsistent.

Of her family members, Sylvia is closest to her daughter, upon whom she relies for emotional and social support, as well as caregiving when needed. Her daughter and granddaughter wonder how best to address their concerns with Sylvia and encourage her to seek out the help they feel she needs.

\section{Disciplinary perspectives}

Ageing and gerontological researchers have pursued a wide variety of disciplinary angles, from medicine, psychology and sociology, to humanities, political science and humanities (Sugar et al., 2014). Although researchers in these fields may share an interest in the complex phenomena of adult ageing, they share no common or unified paradigm. Under the banner of gerontology, for instance, there are numerous disciplinary-based, specialized 
foci; and within each it is possible to find a plurality of theoretical, methodological and practice approaches operating simultaneously (Alwin and Hofer, 2008; Sasser, 2017).

The case you have just read can certainly be examined from such specific, individual disciplinary perspectives. For example, a medical doctor might analyze the presence of comorbidities - the hearing loss, residual impairment from the stroke, a degenerative condition leading to back pain - and how each on their own and taken together impact Sylvia's functioning and quality of life. The doctor might pose questions about the medications Sylvia has been prescribed, whether she's receiving any therapeutic interventions to improve her functional abilities and perhaps suggest additional medical and life-style protocols from which Sylvia might benefit.

By contrast, a psychologist would be keenly interested in the implications of the previous stroke and the potential vascular dementia for Sylvia's cognitive and socioemotional capacities in the present but also as she moves farther into later life. Sylvia's life-long experience of anxiety and depression would be seen as important factors affecting her quality of life. The psychologist would likely want to know about the quality of Sylvia's social support system and living situation in order to get a sense of her daily life context and the extent to which she has positive connections to others and a sense of purpose. She or he would be particularly sensitive to the presence of self-neglect or elder abuse. Perhaps the psychologist would construct a care plan for Sylvia and her family outlining psychotherapeutic activities that she could engage in to help her maintain and even improve her cognitive capacities.

From yet another perspective, a sociologist might wish to focus on how Sylvia's generational placement - she's a leading-edge baby boomer - may have shaped her life chances and expectations in relationship to social structures such as education, work, family life and even older adulthood. Sylvia's individual lived experiences would serve as a window into larger socio-historical patterns and perhaps offer insight into some of the challenges women who share her characteristics might face as they grow older. A sociologist would also be interested in a more local view of the social structures at play that shape Sylvia's ageing experience, such as the age-friendliness of and access to services in the community in which she lives.

While all these perspectives may be valuable, they can only tell part of the story. Taken in isolation, their utility for understanding and dealing effectively and ethically with the case above is quite limited. We will therefore turn next to a perspective that enables such perspectives to co-exist side-by-side: multidisciplinarity.

\section{Multidisciplinary perspectives}

Multidisciplinary perspectives draw upon two or more disciplines in order to better understand or address a certain issue or problem. Unlike interdisciplinary and transdisciplinary activities, there is no mutual influence between the perspectives, nor any effort to integrate them. Rather, the insights gained from a multidisciplinary approach exist alongside each other as different possibilities for addressing facets of a complex phenomenon.

As we saw above, researchers in the fields of ageing and gerontology have largely adopted (uni)disciplinary approaches. However, because insights from these approaches exist side-by-side, these fields - taken as a whole - can be seen as developing in a multidisciplinary manner. In other words, the fields as a whole have articulated - but not integrated - a wide variety of disciplinary angles, from medicine, psychology and sociology, political science and humanities (Sasser, 2017; Sugar et al., 2014). The deeper, integrative and 
empowering approaches of inter- and transdisciplinarity are, as yet, quite rare (Alwin and Hofer, 2008; Sasser, 2017).

While some researchers have made claims about unifying scientific paradigms (see, for example, Ferraro, 2007) that bring together varied approaches, a handful of provocative disciplinary mash-ups and counter-paradigms have emerged to problematize these claims. Notable examples of such alternative approaches include critical gerontology (Biggs, 2005; Wellen, 2018), cultural gerontology (Twigg and Martin, 2015), narrative gerontology (de Medeiros, 2013) and age studies, a hybrid field that emerged as a challenge to mainstream gerontology (Gullette, 2004).

To illustrate a multidisciplinary approach, let us continue with the case above and the three disciplinary perspectives described there: medicine, psychology and sociology. If the three disciplinarians each contributed her or his insights, without any attempt to integrate them, then a multidisciplinary perspective would emerge. Sylvia's situation as presented in the case would be viewed through each of the disciplinary lenses and each would address a different facet or level of the complex situation Sylvia is experiencing: the body, the mind or the social context.

As we have seen above, the medical doctor may view Sylvia's co-morbidities largely as the effect of her various acute and chronic health issues, intensified by normal ageing processes. Her or his primary concern would then be how best to intervene. The psychologist, on the other hand, might focus on Sylvia's functional capacity, emotional well-being and connections with others. She or he might feel strongly that individual and family counseling would be of great benefit to Sylvia, as would cognitive training to help her overcome some thinking habits that are getting in the way of her ability to maintain independence. Finally, the sociologist would likely be interested in the larger social, economic and gender-based norms and forces that have shaped Sylvia's ageing experience.

Multidisciplinary approaches might treat these different perspectives as if they are of equal explanatory power. Or they might seek to determine which has the greatest explanatory power and appears to "fit" the complex situation best.

A multidisciplinary approach would therefore involve moving from one disciplinary perspective to another, trying on each one to see what it might reveal. From a pragmatic standpoint, then, we might ask which level seems to present the most pressing need for intervention in support of Sylvia's well-being: Her complex co-morbidities? Her emotional and mental health? Her living situation, access to services and resources, and social support network? Let's say that we determine that each of these areas should be addressed; a multidisciplinary approach would involve developing different versions of Sylvia's story, each with its own foregrounded issue or problem and corresponding intervention or solution. But there wouldn't be any attempt to synthesize these different approaches into an integrated explanation of Sylvia's situation and possible beneficial, interconnected responses.

\section{Interdisciplinary perspectives}

Many of the most challenging issues society faces today are ones that cannot be fully understood or addressed through single disciplines - or even through multidisciplinary approaches that aggregate differing disciplinary perspectives but do not attempt to integrate them. Examples include poverty, diabetes and climate change. They are complex, messy, "wicked" problems that "cannot be solved by simply applying new information and tools or adding more variables to existing decision models and computer programs" (Klein, 2004). 
As a result, many researchers have called for interdisciplinary approaches that not only draw upon, but also attempt to integrate, disciplinary perspectives in a way that may lead to the development of new, overarching knowledge that transcends these perspectives (Klein, 2017; Repko, 2012). To construct such perspectives, interdisciplinary thinkers have in recent decades developed step-by-step models for bringing together and integrating diverse disciplinary inputs (Repko 2012; Repko, Newell and Szostak, 2012). These models typically include steps such as defining a question, determining relevant disciplines, negotiating roles, identifying conflicts and, especially, creating common ground.

There is dispute about whether common ground can always be found and whether this should even be the driving goal on interdisciplinary work (McMurtry et al., 2012; Sasser and Dreyfuss, 2015). One thing that makes finding common ground challenging is that disciplines' theories and methods often conflict or are incommensurable. As Petrie writes in his classic and influential article on interdisciplinarity, “[q]uite literally, two opposing disciplinarians can look at the same thing and not see the same thing" (1976: 11). Further, one cannot - and should not - attempt to avoid or eliminate these conflicts: "difference, tension, and conflict are not barriers that must be eliminated. They are part of the character of interdisciplinary knowledge negotiation" (Klein, 2005: 45).

Regardless of the position one takes in relation to the above issues, the step models proposed by interdisciplinary thinkers are undeniably useful as a starting point or heuristic for researchers dealing with the challenge of integrating differing disciplinary perspectives.

In the fields of health science and care - related to ageing and gerontology but more general in scope - there has been a push in the past few decades to integrate both research and practice perspectives, as well as to pursue interdisciplinarity in collaborative teams since one person rarely comprehends all the knowledge necessary to solve complex problems (McMurtry, Kilgour and Rohse, 2017; Stokols et al., 2008).

Ageing and gerontology are also considered by many to be fields where interdisciplinary approaches are urgently needed, including approaches that involve collaborating teams of specialists that gather from various fields and disciplines; indeed, some have claimed that the field of gerontology is inherently interdisciplinary (Sasser and Moody, 2018; Schultz, Keyser and Pincus, 2011; Sugar et al., 2014). As we saw above, however, this has not proven to be the case. Much ageing and gerontological research has proceeded in a narrow disciplinary or, at best, multidisciplinary manner.

We will now imagine the case above from the perspective of an interdisciplinary team again, we will consider, for illustration, the medical doctor, the psychologist and the sociologist. Working in an interdisciplinary and collaborative manner, the three professionals would take steps to identify tensions and find commonalities or complementarities in their approaches. For example, the doctor and psychologist might consider the relationship between the chronicity of Sylvia's physical pain, on the one hand, and her functional capacity, emotional well-being and connections with others, on the other. They would hopefully take into account the complex interweavings of physical, mental and social factors and tailor their treatment plans accordingly. For example, they might insure that Sylvia's physical therapy and pharmacology were structured in a manner that would support her counselling and cognitive training - and vice versa. The sociologist might stress the need that such treatments also adopt a critical awareness of how Sylvia's life has been shaped by, for example, economic insecurity, domestic abuse and discrimination based on age or gender.

When interdisciplinary integration works well, therefore, it can produce knowledge or action that is "more-than-the-sum-of-its-parts". That is, people can elicit, build on and challenge one another's insights - in effect, synthesizing differing disciplinary ideas. They 
are empowered to produce new knowledge that exceeds their individual disciplinary understandings - knowledge that could not have been predicted in advance of interdisciplinary collaboration. In concrete terms, such integration may give rise to new research, concepts, terminology, methods, diagnoses, care plans or procedures (McMurtry, Rohse and Kilgour, 2016).

By contrast, without such integration of disciplinary and professional insights, interdisciplinarians would argue, one runs the risk of implementing treatments that interfere or even undermine one another. For example, pain medications that leave Sylvia drowsy might limit the effectiveness of counselling and cognitive training; counselling sessions distant from public transportation routes might risk her physical health and recovery; and treatment or counselling plans that ignore the subject of domestic abuse might be only address superficial issues.

\section{Transdisciplinary perspectives}

While interdisciplinary perspectives offer a broader and more integrated perspective on ageing and gerontology, something important is still missing: the perspectives and participation of people, families and communities who are actually affected by research and other interdisciplinary activities. As we wrote above, the term transdisciplinary has been used to describe research that involves collaboration among not only academic researchers but also non-academic stakeholders (Klein, 2017).

Stakeholder engagement in transdisciplinarity involves more than just consulting people, for example, through consumer-based research. It means actively engaging stakeholders as co-participants in research and change, and viewing them as experts in their own right (about their own experiences). Stakeholder engagement is not alone sufficient, however; Sasser (2017) has added the following additional criteria for genuinely transdisciplinary research:

- $\quad$ embraces and foregrounds complexity, resisting dualisms and other simplistic form of thinking;

- commits to addressing current "wicked problems" while envisioning (and creating) better possible futures;

- $\quad$ recognizes the multiple, interconnected levels and dimensions of life and reality;

- transgresses institutional, disciplinary and paradigmatic boundaries;

- takes on the challenge of communicating and collaborating across differences;

- commits to the difficult work of critical self-reflection on one's own lived experiences and attempts to live transdisciplinarity life-wide; and

- makes room for play, creativity, spirituality, the unconscious and that which cannot be contained or explained.

Echoing this transdisciplinary ethos (though not explicitly naming his "participatory enactment" approach transdisciplinary) Biggs urges:

[I]t follows that research would need to be undertaken in a spirit of partnership that both parties interrogate ageing from their particular perspective and the reciprocal skills and aptitudes of each party are made recognizable. Growing interest in the role of older people in social research requires a detailed analysis of the strengths and weaknesses of different age groups as researchers, with no party playing servant to the other. 
In recent years, there has been a call for transdisciplinary approaches to research from a wide variety of fields, from philosophy to healthcare and sustainability (td-net, 2019; McMurtry, Kilgour and Rohse, 2017). Within the areas of ageing and gerontology specifically, a small number of thinkers have begun to articulate the need for transdisciplinary and similar approaches (Biggs, 2005; Proctor, 2001; Sasser, 2017).

Drawing again upon the case above, a transdisciplinary approach would first and foremost foreground the complexity of the situation presented and background the various (multi- and inter-) disciplinary perspectives contributing to the development of a rich, synthetic understanding. We (since we consider ourselves transdisciplinarians) would begin our exploration thick in the complexity of the situation and bring in the various perspectives - uni-, multi- and interdisciplinary - we described above.

In addition, there would be an intentional commitment to discovering ways into the experiences of each family member as well as the family system as a complicated whole. In other words, the potential participants to include (in the process of inquiring more deeply into the various intertwined issues embedded in the case) would be Sylvia, her daughter, her granddaughter, as well as other close-in people who are an important part of Sylvia's milieu. This group might also encompass her care providers, neighbors, current close friends and other family members, perhaps as well as persons not yet identified, such as a member of the clergy, a new or previous partner, or a pet.

Identifying who these important persons are in Sylvia's current lifeworld would begin, of course, with asking her who she considers to be members of her "inner circle". It is quite possible that, given the current conflict with her daughter and granddaughter, they would not be identified; this would be important information in and of itself and could lead to a question regarding where Sylvia currently situates her daughter and granddaughter in her daily life. It is certainly not necessary to include every member of Sylvia's relationship network in the inquiry and subsequent planning process. But knowing who these members are from Sylvia's perspective (as well as from her daughter's and granddaughter's perspectives) provides significant context upon which to co-create a deeper understanding of her current situation.

Related to this, we would expect that the case as presented to us is only a partial representation of the complex situation in which Sylvia, her daughter and granddaughter are embedded. We would therefore ask probing questions to help us discover whether there are other life-long or current issues contributing to the complex situation. We would first ask questions grounded in experience and meaning, for example: What is most important to you in your life right now? When do you feel most contented and satisfied with how your life is going? What gives your life a sense of purpose and meaning? What are some of your biggest concerns or challenges? When you think about the next few months, do you have any ideas about things you'd like to do that would help you manage these concerns and challenges? Notice that these questions do not just identify problems and solutions; they honor Sylvia's agency as an individual and encourage appreciation and creativity. These and other questions like them signal that the ageing journey is the human journey, that ageing is a process of growth and not just loss, and that even in the context of great challenges there are opportunities for change.

While we as transdisciplinary researchers are committed to resisting dualistic and reductionistic thinking, we would also want to ask questions that touched on the various multifacets of Sylvia's experience: body, mind, spirit in context (or, to put it in more disciplinary terms, the biophysical, emotional, cognitive, social, environmental, economic, etc.). We would then harness (multi- and inter-) disciplinary perspectives and insights as appropriate. 
Approaching this case as a transdisciplinary gerontological endeavor would mean that we would frame Sylvia's complex situation as, first and foremost, an adult ageing situation (as opposed to a medical or mental health or neurological or family systems issue; all of these areas and more are intertwined in the case). This means that we would bring to bear what gerontology as a field tells us about the "normal" adult ageing experience; how it is a process of gains, losses and stability in functioning across multiple domains; how it unfolds across the long life-course and is strongly shaped by the contexts in which it occurs; and how ageing is expressed at the individual level and with great variability. This means that we would strive to disentangle the developmental challenges - for Sylvia as well as her family members - of different life-course stages, from ageing-related (but not caused by ageing itself) mental and physical health challenges, to life-long patterns of functioning that are exerting an influence on current functioning.

\section{Epistemological implications/complications}

Multidisciplinary, interdisciplinary and transdisciplinary research prompt one toward more pluralistic epistemological perspectives. After all, if quantitative and qualitative, natural sciences and social sciences - not to mention the humanities - can all offer valuable insights into a particular topic or problem, then it is difficult to cling to the notion that any particular disciplinary approach "owns" the truth (Welch, 2012).

Most interdisciplinarians accommodate this plurality of epistemological perspectives. As in other fields, however, few explicitly challenge two deeply entrenched and conventional assumptions about knowledge: (1) that it must be framed in terms of correspondence between an external objective world and our subjective understandings or "representations" of it, and (2) that we are moving toward a complete or comprehensive understanding of the world (McMurtry and Dellner, 2014; McMurtry and McMurtry, 2016).

A frequently invoked parable in naive interdisciplinary writing is one about the blind men and the elephant. In it, each blind man feels a different part of the elephant. The one who feels the trunk, for example, concludes that an elephant is like a snake, while the one who touches the leg thinks it is like a tree. The king, or rajah, who watches this process, however, puts all the pieces together to acquire a supposedly complete or comprehensive understanding of the elephant.

This epistemological assumption underlies much interdisciplinary research: while disciplines accurately describe slices or facets of reality, interdisciplinary research can provide the "big picture". As Klein and Newell write in their oft-quoted definition of interdisciplinary studies:

A process of answering a question, solving a problem, or addressing a topic that is too broad or complex to be dealt with adequately by a single discipline or profession.... [It] draws on disciplinary perspectives and integrates their insights through construction of a more comprehensive perspective.

(1997: 393-415)

We, however, believe that inter- and transdisciplinarity present an even deeper challenge to conventional epistemologies: they prompt us to move beyond a notion of knowledge as correspondence between objective realities and subjective representations, as well as the conviction that we are moving toward more complete and comprehensive understandings of the world. 
Let's start with subjectivity and objectivity, the two poles that delimit most commonsense discussions of knowledge. While we view all disciplinary knowledge as situated and partial, that does not mean that it is entirely subjective. After all, our physical and social worlds place hard limits on what knowledge can work. For instance, believing that we can fly will not help us if we jump off a building without a parachute, and treating our students like serfs will probably get us fired. Similarly, disciplinary, multi-, inter- and transdisciplinary knowledge must work effectively in the contexts in which it is employed.

This does not mean, however, that the world dictates one specific objective or complete truth. For example, many different sorts of knowledge have helped people in different cultures to grow agricultural crops, construct buildings, navigate using celestial bodies like stars or negotiate social structures like families, workplaces or governments. Furthermore, as Kuhn (1970) and others have shown, paradigms are revolutionized or reformulated on a fairly regular basis. What we used to think was an objective representation of the world has usually turned out to be an imperfect human construction - albeit, like Newtonian physics, a very useful one. As Einstein and Infeld put it, "[p]hysical concepts are free creations of the human mind, and are not, however it may seem, uniquely determined by the external world" (1967: 3).

Indeed, many researchers in the past two decades have argued that complex systems (like human beings, social collectives, cities, economies and ecologies) are never entirely reducible to any overarching rules or laws (Sasser and Dreyfuss, 2015; McMurtry, 2011). As Osberg, Biesta and Cilliers write:

$[\mathrm{M}]$ odels and theories that reduce the world to a system of rules or laws cannot be understood as pure representations of a universe that exists independently, but should rather be understood as valuable but provisional and temporary tools by means of which we constantly re-negotiate our understanding of and being in the world.

(2008: 218)

There is no final truth of the matter, only increasingly diverse ways of interacting in a world that is becoming increasingly complex (223).

What this means for research on ageing and gerontology, is that we should both (1) respect and value the disciplinary and multi-, inter- and transdisciplinary knowledge we construct and (2) acknowledge and embrace the fact that it is evolving as we as researchers and practitioners collectively expand, challenge and elaborate on it. There is no final, objective or complete truth; that is not the job of human knowledge. Its job is more pragmatic: to provide (hopefully) ever more effective, nuanced, ethical and empowering tools for interacting with our shared physical, social and ecological worlds.

\section{References}

Alwin, D.F. and Hofer, S.M. (2008). Opportunities and challenges for interdisciplinary research. In: S.M Hofer and D.F. Alwin (eds), Handbook of cognitive ageing: interdisciplinary perspectives. Thousand Oaks, CA: Sage.

Augsburg, T. (2014). Becoming transdisciplinary: the emergence of the transdisciplinary individual. World Futures: The Journal of New Paradigm Research, 70(3-4), 233-247.

Bernstein, J.H. (2015), Transdisciplinarity: a review of its origins, development, and current issues. Journal of Research Practice, 11(1), article R1. http:/jrp.icaap.org/index.php/jrp/article/view/510/412.

Biggs, S. (2005). Beyond appearances: perspectives on identity in later life and some implications for method. Journal of Gerontology, 60(3), 118-128. 
Byrne, E., Mullally, G. and Sage, C. (eds) (2016). Transdisciplinary perspectives on transitions to sustainability. Oxford: Routledge.

De Medeiros, K. (2013). Narrative gerontology in research and practice. New York: Springer Publications.

Einstein, A. and Infeld, L. (1967). The evolution of physics. New York: Simon \& Schuster.

Ferraro, K. (2007). Is gerontology interdisciplinary? Journals of Gerontology: Social Sciences, 62(1), S2.

Gullette, M.M. (2004). Aged by culture. Chicago, IL: University of Chicago Press.

Klein, J. (2004). Interdisciplinarity and complexity: an evolving relationship. E:CO, 6(1-2), 2-10.

Klein, J. (2005). Interdisciplinary teamwork: the dynamics of collaboration and integration. In: S. Derry, C. Schunn and M. Gernsbacher (eds), Interdisciplinary collaboration: an emerging cognitive science. Mahwah, NJ: Lawrence Erlbaum.

Klein, J. (2017). Typologies of interdisciplinarity: the boundary work of definition. In: R. Frodeman, J. Thompson Klein and R.C.S. Pacheco (eds), The Oxford handbook of interdisciplinarity. 2nd ed. Oxford: Oxford University Press.

Klein, J. and Newell, W. (1997). Advancing interdisciplinary studies. In: J. Gaff and J. Ratcliff (eds), Handbook of the undergraduate curriculum: a comprehensive guide to purposes, structures, practices and change. San Francisco, CA: Jossey-Bass.

Kuhn, T.S. (1970). The structure of scientific revolutions. Chicago, IL: Chicago University Press.

McMurtry, A. (2011). The complexities of interdisciplinarity: integrating two different perspectives on interdisciplinary research and education. Complicity: An International Journal of Complexity and Education, 8(2), 19-35.

McMurtry, A. and Dellner, J. (2014). Relationalism: an interdisciplinary epistemology. Or, why our knowledge is more like a coral reef than fish scales. Integrative Pathways: Newsletter of the Association for Interdisciplinary Studies, 36(3), 6-12.

McMurtry, A. and McMurtry, R.Y. (2016). More productive ways to think about learning, knowledge and education. Medical Education, 50(11), 1091-1093.

McMurtry, A., Clarkin, C., Bangou, F., Duplaa, E., Macdonald, C., Ng-A-Fook, N. and Trumpower, D.L. (2012). Making interdisciplinary collaboration work: key ideas, a case study and lessons learned. Alberta Journal of Educational Research, 58(3), 461-473.

McMurtry, A., Kilgour, K.N. and Rohse, S. (2017). Health research, practice and education. In: R. Frodeman, J. Thompson Klein and R.C.S. Pacheco (eds), The Oxford handbook of interdisciplinarity. 2nd ed. Oxford: Oxford University Press.

McMurtry, A. Rohse, S. and Kilgour, K.N. (2016). Sociomaterial perspectives on interprofessional team and collaborative learning. Medical Education, 50(2), 169-180.

Osberg, D., Biesta, G. and Cilliers, P. (2008). From representation to emergence: complexity's challenge to the epistemology of schooling. Educational Philosophy and Theory, 40(1), 213-227.

Petrie, H. (1976). Do you see what I see? The epistemology of interdisciplinary inquiry. Educational Researcher, 5(2), 9-15.

Proctor, G. (2001). Listening to older women with dementia: relationships, voices and power. Disability \& Society, 16(3), 361-376.

Repko, A. (2012). Interdisciplinary research: process and theory. 2nd ed. Thousand Oaks, CA: Sage.

Repko, A.F., Newell, W.H. and Szostak, R. (2012). Case studies in interdisciplinary research. Thousand Oaks, CA: Sage.

Sasser, J.R. (2014). Transforming trauma through reflection and praxis: embracing the principles of critical educational gerontology life-wide. SAGE Open, 4, 1-10.

Sasser, J.R. (2017). Our research is living, our data is life: toward a transdisciplinary gerontology. Issues in Interdisciplinary Studies, 35, 14-28.

Sasser, J.R. and Dreyfuss, S. (2015). Enacting integration: two case studies, three principles. In: P.C. Hughes, J.S. Munoz and M.N. Tanner (eds), Perspectives in interdisciplinary and integrative studies. Lubbock, TX: Texas Tech University Press.

Sasser, J.R. and Moody, J.R. (2018). Gerontology: the basics. Oxford: Routledge. 
Schultz, D., Keyser, D. and Pincus, H.A. (2011). Developing interdisciplinary centers in ageing: learning from the RAND/Hartford Building Interdisciplinary Geriatric Health Care Research Centers initiative. Academic Medicine, 86(10), 1318-1324.

Stokols, D., Hall, K.L., Taylor, B.K., Moser, R.P. and Syme, S.L. (2008). The science of team science: assessing the value of transdisciplinary research. American Journal of Preventive Medicine, 35(2), S77-S252.

Sugar, J.A., Riekse, R.J., Holstege, H. and Faber, M.A. (2014). Introduction to ageing: a positive, interdisciplinary approach. New York: Springer Publishing Company.

Szostak, R. (2013). Interdisciplinary research. About Interdisciplinarity. Available at: https://sites.google. com/a/ualberta.ca/rick-szostak/research/about-interdisciplinarity/best-practices/interdisciplinaryresearch [Accessed 28 August 2019].

td-net (2019). Network for Transdisciplinary Research, Swiss Academy of Arts and Sciences, www. transdisciplinarity.ch.

Twigg, J. and Martin, W. (2015). The challenge of cultural gerontology. Gerontologist, 55(3), 353-359.

Welch, J. (2012). Interdisciplinarity and the question of being. Issues in Integrative Studies, 30, 99-122.

Wellen, C. (Ed.) (2018). Critical gerontology comes of age: advances in research and theory for a new century. Oxford: Routledge. 